\title{
CT-Guided Percutaneous Radiofrequency Thermal Ablation of Osteoid Osteoma
}

\section{Pedro Manuel Serrano*, João Maia Rosa, Luís Coutinho, Marta Santos Silva, Vânia Oliveira and Pedro Cardoso Serviço de Ortopedia e Traumatologia, Portugal}

*Corresponding author: Pedro Manuel Serrano, Serviço de Ortopedia e Traumatologia, Hospital de Santo António, Portugal

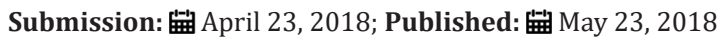

\section{Abstract}

The purpose of this work was to describe our experience in treating osteoid osteomas (00), using percutaneous computed tomography (CT)guided radiofrequency ablation (RFA).

Materials and methods: Retrospective review of 48 patients with 00, treated with percutaneous RFA, in the same institution, from 2003 to 2015 Clinical success, assessed at a minimum follow-up of 1 year, was defined as complete pain relief. Early and late complications as well as local recurrences were recorded.

Results: Clinical success was achieved in 45 patients (93.75 \%). After RFA, mean Visual Analogue Scale (VAS) significantly improved from $7 \pm 1$ to $1 \pm 1(\mathrm{p}<0.05)$. Recurrence was found in one patient with an 00 of the proximal humerus, associated with pain. Two other patients presented complications related to the procedure. There were no long-term complications.

Conclusion: CT-guided RFA of osteoid osteomas is a safe and effective procedure with a low morbidity rate.

Keywords: Osteoid osteoma; Bone tumour; Radiofrequency ablation; Computed tomography

\section{Introduction}

Osteoid osteoma (00) is a benign, small, painful, round or oval, bone tumor (Figure $1 \& 2$ ), with limited growth potential, that occurs most commonly in children, adolescents, and young adults between the ages of 5 and 30 [1,2]. It represents around
$12 \%$ of benign bone lesions, and is most frequently located in long bones of the lower extremities [3]. Most 00 are symptomatic. Pain is described as dull and aching, worse at night, and responsive to nonsteroidal anti-inflammatory (NSAID) medication $[3,4]$.

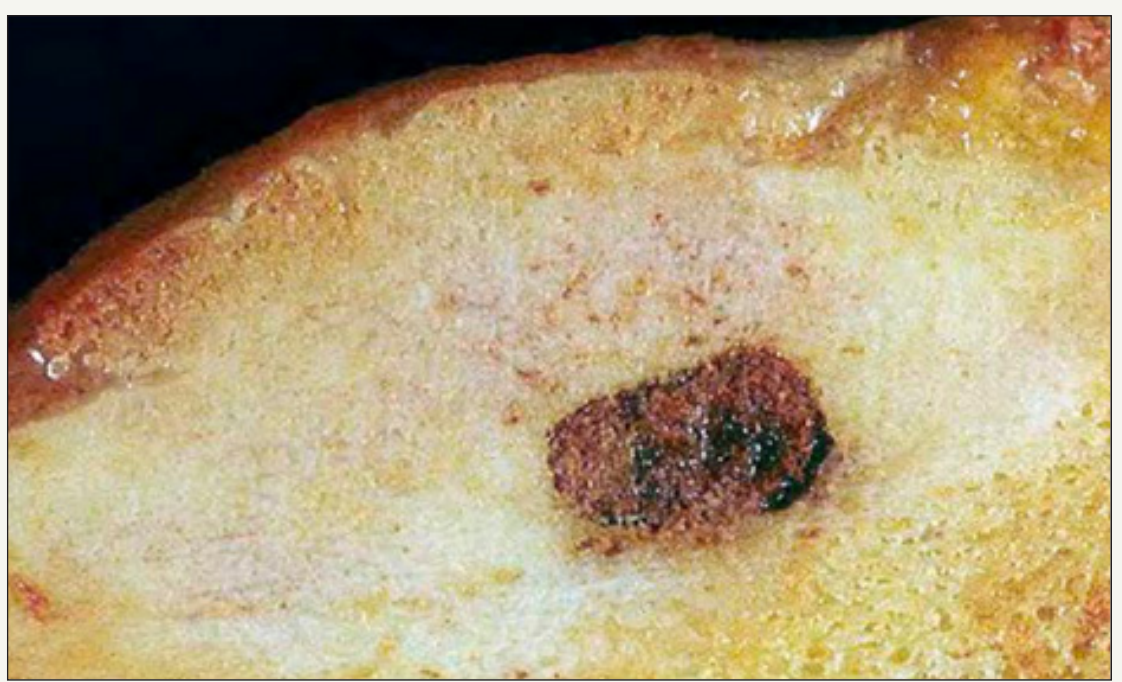

Figure 1: Macroscopic aspect of an Osteoid Osteoma. 


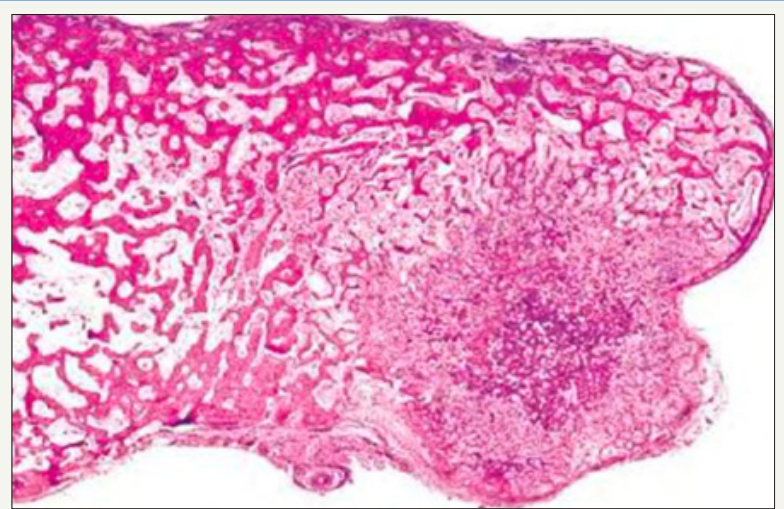

Figure 2: Microscopic aspect of an Osteoid Osteoma.

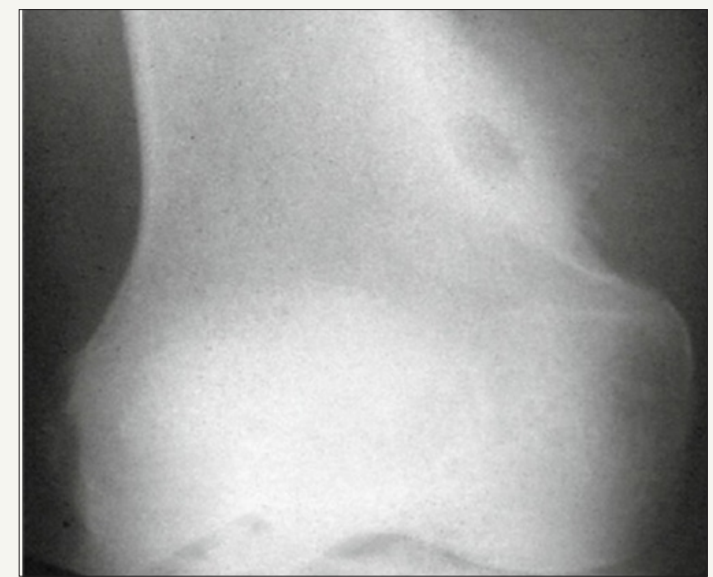

Figure 3: Plain radiograph of the distal femur, with a clear image of the "nidus".

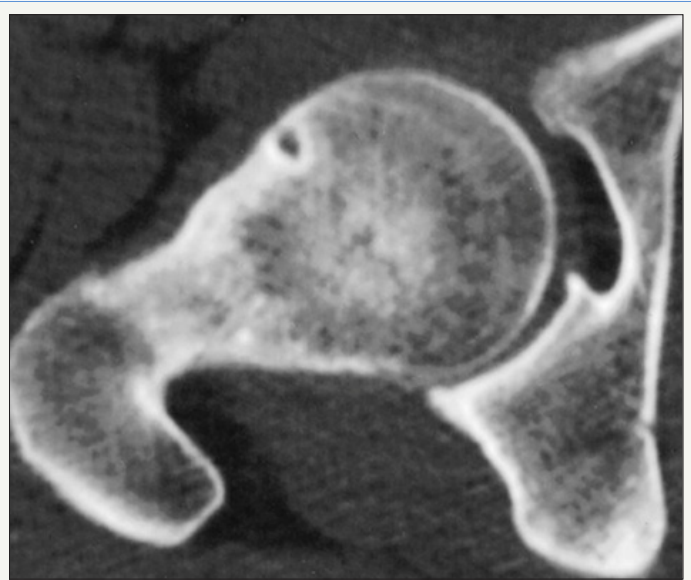

Figure 4: CT Scan of the proximal femur, allowing for a more precise location of the tumor.

The basic radiological element is a distinctive small rounded area of osteolysis, the 'nidus', which consists of osteoid tissue surrounded by a halo of hyperostosis on radiographs (Figure 3) and CT Scans (Figure 4), or signal intensity on Magnetic Resonance Imaging (MRI) [5].

The standard historical treatment for these lesions has been surgical resection [6], however due to the potential surgical complications related to surgery, percutaneous radiofrequency ablation (RFA) has been considered, recently, as an attractive minimally invasive alternative, due to less bone destruction and shorter hospitalization, with clinical response and safety [7], regardless of anatomic location. However, given the absence of pre-operative histological confirmation, diagnosis through clinical assessment and imaging should be as accurate as possible. Additional precautions must be taken when neurovascular bundles or neurological structures are near. Cannulated drills or biopsy needles are a useful option to safely assess the path to the nidus. Injection of gas or a refrigerated liquid in the epidural space as a protective barrier between the nidus and the spinal cord is also an option [8]. The aim of this work is to report our experience in treating 00 and to assess the efficacy of RFA as the standard treatment method.

\section{Material and Methods}

A retrospective case series study was conducted at a tertiary Centre, with the approval of the hospital ethics committee. Between January 2003 and December 2015, a total of 48 patients (30 male, 18 female; mean age 22 years; range $9-43$ years) with 00 were treated in our institution. All patients were symptomatic. The duration of pain ranged from seven months to three years. The decision of treatment was made on the basis of clinical and radiological criteria. Clinical criteria included worsened pain at night that relieve with NSAIDs. Radiological criteria were based on radiographs (X-Ray), CT or MRI. When diagnostic doubts persisted, patients underwent surgical resection.

All procedures were performed by the same orthopedic surgeon, under general or spinal anesthesia. Skin and material preparation was performed in the same manner as it is for a needle biopsy. For most patients with limb lesions, supine positioning was preferred. The limb was rotated to best suit the surgeon and secured with straps to allow for good skin access and easier needle placement. In spinal 00 the patient was lying prone with a padded ring beneath the chest for easier ventilation.
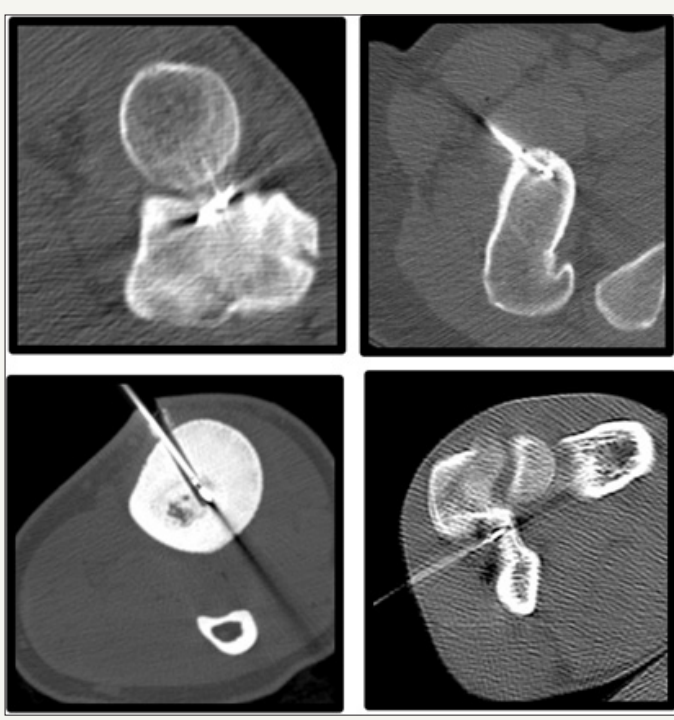

Figure 5: CT-guided percutaneous RFA with a 20-gauge needle. 
A trephine needle with an outer diameter of $2 \mathrm{~mm}$ was introduced into the lesion (it is important to select the best entry point and course for the needle, in relation to the different anatomical locations and nearby structures). A cool-tip electrode, with an outer diameter of $1 \mathrm{~mm}$ and built-in temperature thermistor is placed in the same hole, heating the lesion up to $90{ }^{\circ} \mathrm{C}$ for 6 minutes (Figure 5). A simple bandage is applied to the puncture site. Patients are allowed to fully weight-bare immediately.

Clinical success was assessed at a minimum follow-up of 1 year and defined as complete pain relief. Pain and clinical outcomes were scored pre- and postoperatively using the visual analogue scale (VAS). Early and late complications as well as local recurrences were recorded.

\section{Results}

A total of 48 patients ( 30 males, 18 females; mean age 22 years; range 9-43 years) with 00 were included. Most lesions were located in the lower limb as shown (Table 1). Clinical success was achieved in 45 patients (93.75\%). After RFA, mean VAS score significantly improved from $7 \pm 1$ to $1 \pm 1$ ( $p<0.05$ ). Most patients referred pain relief in the first 48 hours. Local recurrence was found in one patient with an 00 of the proximal humerus, associated with pain. This patient underwent a second ablation, however, at maximum follow-up, residual pain was still present.

Table 1: Anatomical distribution of the lesions.

\begin{tabular}{|c|c|}
\hline Anatomical Location & Number \\
\hline Upper Limb & $\mathbf{7}$ \\
\hline Proximal humerus & 2 \\
\hline Elbow & 3 \\
\hline Radial Shaft & 1 \\
\hline Ulnar Shaft & 1 \\
\hline Lower Limb & $\mathbf{3 7}$ \\
\hline Proximal femur & 19 \\
\hline Distal femur & 9 \\
\hline Tibia & 6 \\
\hline Acetabulum & 2 \\
\hline Iliac crest & 1 \\
\hline Spine & $\mathbf{4}$ \\
\hline Vertebral body of D8 & 1 \\
\hline Pediculum of L2 & 1 \\
\hline Pediculum of L4 & 1 \\
\hline Second sacral vertebra & 1 \\
\hline
\end{tabular}

Seven located in the upper limb (proximal humerus, $\mathrm{n}=2$; elbow, $\mathrm{n}=3$; radial shaft, $\mathrm{n}=1$; ulnar shaft, $\mathrm{n}=1$ ).

37 in the lower limb (proximal femur, $\mathrm{n}=19$; distal femur, $\mathrm{n}=9$; acetabulum, $\mathrm{n}=2$; iliac crest, $\mathrm{n}=1$; tibia, $\mathrm{n}=6$ ).

4 in the spine (vertebral body of D8, pediculum of L2, pediculum of $\mathrm{L} 4$, second sacral vertebra).
One of the patients that underwent lumbar thermo ablation with gas injection in the epidural space (as a protective measure due to its proximity to neurological structures) initiated an aseptic meningitis syndrome postoperatively. Full recovery was achieved after 4 days. Another patient referred a transient severe sciatic pain after surgery that disappeared after 48 hours. Two patients with 00 of the tibial shaft developed osteomyelitis after RFA. One occurred due to infection of the needle path with a methicillin sensitive Staphylococcus aureus and underwent 4 weeks of antibiotherapy. The other, was in fact a Brodie abscess, that was mistakenly diagnosed as an 00 at the initial assessment. No other complications were detected after RFA.

\section{Discussion}

The purpose of treating patients with osteoid osteoma is to destroy the nidus, and subsequently, eliminate the symptoms [9]. Traditional treatments have a success rate of over $90 \%$ in some published series, and may range from open resection and curettage to wide resections with bone grafting and bone fixation [10]. However, the complication rate following surgical resection can be high, with authors reporting values from 20 to $40 \%$. In addition, open surgery is associated with higher morbidity, the risk of recurrence, longer hospital stays, higher costs for the patient, and possible damage to the physis or adjacent joints $[10,11]$. Although, surgery still has specific indications in these tumors, CT-guided thermal ablation is, nowadays, a minimally invasive alternative, that requires simple and inexpensive equipment, and allows for similar outcomes, with success rates ranging from 77 to $100 \%$ [10].

To our knowledge, this study represents the largest series of 00 treated in our country, and one of the largest series overall, treated with RFA. With $93,75 \%$ of patients referring complete pain relief, we consider this procedure, not only minimally invasive, but also highly effective and safe for treating osteoid osteomas.

Other techniques, such as laser interstitial thermal therapy, seem to share many of the advantages and efficiency of CT-guided radiofrequency thermoablation [12], however, this procedure is not as readily available for hospital use, and more clinical studies are needed to confirm its value. Cryotherapy, ethanol therapy and imaging-guided excision remain second-line therapies [10].

Regardless of the treatment method, success is highly dependent on nidus location [13], and the main challenge of CTguided RFA remains the lack of histological diagnosis; not the procedure itself. We believe that a surgical biopsy should still be considered, whenever there is doubt in diagnosis, however, the actual developments of imaging available nowadays allow for a continually improved diagnostic accuracy.

\section{Conclusion}

CT-guided RFA of osteoid osteomas is a safe and extremely effective treatment presenting 94\% complete pain relief after a single procedure and nowadays should be assumed as the standard treatment for these patients. Even when recurrence of symptoms occurs, this treatment can be performed again with positive 
response. In this large series, complications were not frequent, and all were temporary. Nevertheless, diagnostic of 00 should be accurate, preferably at a referral Centre.

\section{References}

1. Pinto $\mathrm{CH}$, Taminiau AH, Vanderschueren GM, Hogendoorn PC, Bloem JL, et al. (2002) Technical considerations in CT-guided radiofrequency thermal ablation of osteoid osteoma: tricks of the trade. AJR Am J Roentgenol 179(6): 1633-1642.

2. Virayavanich W, Singh R, O’Donnell RJ, Horvai AE, Goldsby RE, et al. (2010) Osteoid osteoma of the femur in a 7-month-old infant treated with radiofrequency ablation. Skeletal Radiol 39(11): 1145-1149.

3. Rosenthal DI, Springfield DS, Gebhardt MC, Rosenberg AE, Mankin HJ (1995) Osteoid osteoma: percutaneous radio-frequency ablation. Radiology 197(2): 451-454.

4. Gasbarrini A, Cappuccio M, Bandiera S, Amendola L, van Urk P, et al. (2011) Osteoid osteoma of the mobile spine: surgical outcomes in 81 patients. Spine (Phila Pa 1976) 36(24): 2089-2093.

5. Wang B, Han SB, Jiang L, Yuan HS, Liu C, et al. (2017) Percutaneous radiofrequency ablation for spinal osteoid osteoma and osteoblastoma. Eur Spine J 26(7): 1884-1892.

6. Barei DP, Moreau G, Scarborough MT, Neel MD (2000) Percutaneous radiofrequency ablation of osteoid osteoma. Clin Orthop Relat Res (373): 115-124.
7. Endo RR, Gama NF, Nakagawa SA, Tyng CJ, Chung WT, et al. (2017) Osteoid osteoma - radiofrequency ablation treatment guided by computed tomography: a case series. Rev Bras Ortop 52(3): 337-343.

8. Rybak LD, Gangi A, Buy X, La Rocca Vieira R, Wittig J (2010) Thermal ablation of spinal osteoid osteomas close to neural elements: technical considerations. AJR Am J Roentgenol 195(4): W293-298.

9. Maurer MH, Gebauer B, Wieners G, De Bucourt M, Renz DM, et al. (2012) Treatment of osteoid osteoma using CT-guided radiofrequency ablation versus MR-guided laser ablation: a cost comparison. Eur J Radiol 81(11): e1002-1006.

10. Cantwell CP, Obyrne J, Eustace S (2004) Current trends in treatment of osteoid osteoma with an emphasis on radiofrequency ablation. Eur Radiol 14(4): 607-617.

11. Magre GR, Menendez LR (1996) Preoperative CT localization and marking of osteoid osteoma: description of a new technique. J Comput Assist Tomogr 20(4): 526-529.

12. Gangi A, Dietemann JL, Clavert JM, Dodelin A, Mortazavi R, et al. (1998) Treatment of osteoid osteoma using laser photocoagulation. Apropos of 28 cases. Rev Chir Orthop Reparatrice Appar Mot 84(8): 676-684.

13. Karagoz E, Ozel D, Ozkan F, Ozel BD, Ozer O, et al. (2016) Effectiveness of Computed Tomography Guided Percutaneous Radiofrequency Ablation Therapy for Osteoid Osteoma: Initial Results and Review of the Literature. Pol J Radiol 81: 295-300.
Creative Commons Attribution 4.0 International License

For possible submissions Click Here

\section{Submit Article}

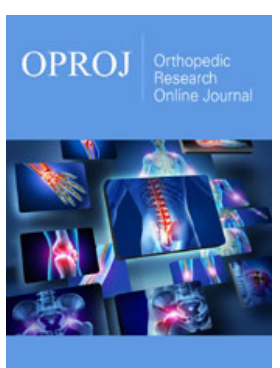

Orthopedic Research Online Journal

\section{Benefits of Publishing with us}

- High-level peer review and editorial services

- Freely accessible online immediately upon publication

- Authors retain the copyright to their work

- Licensing it under a Creative Commons license

- Visibility through different online platforms 